\title{
Infrared Spectroscopy of Niobium Oxide Cluster Cations in a Molecular Beam: Identifying the Cluster Structures
}

\author{
André Fielicke, ${ }^{*, \dagger}$ Gerard Meijer, ${ }^{\dagger, \neq, \S}$ and Gert von Helden ${ }^{\dagger}$ \\ Contribution from FOM Institute for Plasma Physics Rijnhuizen, Edisonbaan 14, \\ NL-3439 MN Nieuwegein, The Netherlands, Department of Molecular and Laser Physics, \\ University of Nijmegen, Toernooiveld 1, NL-6525 ED Nijmegen, The Netherlands, and \\ Fritz-Haber-Institut der Max-Planck-Gesellschaft, Faradayweg 4-6, D-14195 Berlin, Germany \\ Received October 10, 2002; E-mail: fielicke@rijnh.nl
}

\begin{abstract}
Infrared spectra of niobium oxide cluster cations are measured via IR multiple photon dissociation spectroscopy in the $400-1650 \mathrm{~cm}^{-1}$ region. The cluster cations are obtained directly from a laser vaporization source and irradiated with the infrared light emitted by a free electron laser. For those oxide clusters that fragment after excitation, the IR spectra are recorded by measuring the cluster intensity changes as a function of the IR wavelength. The spectra of all examined oxide clusters exhibit two main absorption features that can be assigned to vibrations of terminal $(\mathrm{Nb}=\mathrm{O})$ or bridging $(\mathrm{Nb}-\mathrm{O}-\mathrm{Nb})$ oxide groups. For selected clusters DFT calculations at the B3LYP/LACVP* level have been performed and the calculated vibrational spectra are compared to the experimental data to identify the gas phase structures of the clusters.
\end{abstract}

\section{Introduction}

Niobium oxide has an outstanding potential for catalytic purposes, similar to the oxides of its lighter homologue vanadium. Its application ranges over usage as support material, in catalysts for selective hydrocarbon oxidation up to its role in $\mathrm{NO}_{x}$ conversion for exhaust gas purification. ${ }^{1,2}$ Furthermore, the pentoxide works as a solid acid catalyst, since it possess the behavior of a strong Lewis acid, whereas the hydrated phases ("niobic acid") are Brønsted acids. Due to the acidity, it catalyzes alkene isomerizations or polymerizations, oxidative dehydrogenations, and dehydration reactions, e.g., the isomerization of 1-butene ${ }^{3}$ or the aldol condensation of acetone. ${ }^{4}$

With the aim of modeling isolated active centers of the niobium oxide, free gas phase niobium oxide clusters have been the subject in a few recent studies. These investigations were started by Sigsworth and Castleman with their studies on gas phase reactions of the anions $\mathrm{NbO}_{3}{ }^{-}, \mathrm{NbO}_{5}{ }^{-}$, and $\mathrm{NbO}_{2}(\mathrm{OH})_{2}{ }^{-}$ with $\mathrm{O}_{2}, \mathrm{HCl}$, and $\mathrm{H}_{2} \mathrm{O} .{ }^{5}$ Later, the chemistry of reactions of $\mathrm{NbO}_{3}{ }^{-}$and anionic clusters $\mathrm{Nb}_{x} \mathrm{O}_{y}{ }^{-}$with methanol and ethanol were analyzed by Jackson et al. ${ }^{6,7}$ On the basis of the observed reactions patterns, three isomeric structures for $\mathrm{Nb}_{3} \mathrm{O}_{8}{ }^{-}$are proposed.

Also the properties of cationic niobium oxide clusters have been recently studied by Castleman's group. On the basis of

\footnotetext{
†OM Institute for Plasma Physics Rijnhuizen.

$\doteqdot$ University of Nijmegen.

$\S$ Fritz-Haber-Institut der Max-Planck-Gesellschaft.

(1) Wachs, I. E.; Briand, L. E.; Jehng, J.-M.; Burcham, L.; Gao, X. Catal. Today 2000, 57, 323-330.

(2) Ushikubo, T. Catal. Today 2000, 57, 331-338.

(3) Iizuka, T.; Ogasawara, K.; Tanabe, K. Bull. Chem. Soc. Jpn. 1983, 56, 2927-2931.

(4) Paulis, M.; Martín, M.; Soria, D. B.; Díaz, A.; Odriozola, J. A.; Montes, M. Appl. Catal. A 1999, 180, 411-420.

(5) Sigsworth, S. W.; Castleman, A. W., Jr. J. Am. Chem. Soc. 1992, 114, 10471-10477.
}

10.1021/ja0288946 CCC: $\$ 25.00$ @ 2003 American Chemical Society their experiments on collision-induced dissociation (CID) and $\mathrm{ab}$ initio HF calculations with the $3-21 \mathrm{G}^{*}$ basis they propose tree-like cluster structures, built up from $\mathrm{NbO}_{3}$ units. ${ }^{8}$ For clusters that contain excess oxygen (with regard to a formal oxidation state of +5 for the niobium atoms) loss of oxygen has been observed. $\mathrm{Nb}_{3} \mathrm{O}_{8}{ }^{+}$is observed to lose atomic $\mathrm{O}$ at 0.9 $\mathrm{eV}$ center-of-mass energy, and for $\mathrm{Nb}_{3} \mathrm{O}_{9}{ }^{+}$and $\mathrm{Nb}_{4} \mathrm{O}_{11}{ }^{+}$loss of $\mathrm{O}_{2}$ is induced already under thermal conditions. This behavior is also observed in studies of reactions with $n$-butane, ethane, and ethene: oxygen is released and in some cases adducts with hydrocarbons are formed. ${ }^{9-11}$

DFT calculations by Sambrano et al. ${ }^{12}$ have been inspired by the results from the CID experiments. ${ }^{8}$ Geometric, thermodynamic, and electronic properties of small neutral and cationic niobium oxide clusters starting with $\mathrm{NbO}_{2}{ }^{0 /+}$ up to $\mathrm{Nb}_{3} \mathrm{O}_{8}{ }^{0 /+}$ were investigated. For the larger clusters $\mathrm{Nb}_{3} \mathrm{O}_{7}{ }^{0 /+}$ and $\mathrm{Nb}_{3} \mathrm{O}_{8}{ }^{0 /+}$ open structures (but no cages) are proposed.

Since the knowledge of the geometric and electronic structure is fundamental for understanding the behavior of the cluster, several experimental methods have been applied to attack this problem. CID and reactivity measurements give indirect information on the cluster structure. Anion photoelectron spectroscopy (PES) has been successfully applied in combination with

(6) Jackson, P.; Fisher, K. J.; Willett, G. D. Int. J. Mass Spectrom. 2000, 197 95-103.

(7) Jackson, P.; Fisher, K. J.; Willett, G. D. Chem. Phys. 2000, 262, 179187.

(8) Deng, H. T.; Kerns; K. P.; Castleman, A. W., Jr. J. Phys. Chem. 1996, $100,13386-13393$.

(9) Zemski, K. A.; Justes, D. R.; Bell, R. C.; Castleman, A. W., Jr. J. Phys. Chem. A 2001, 105, 4410-4417.

(10) Zemski, K. A.; Justes, D. R.; Castleman, A. W., Jr. J. Phys. Chem. A 2001 $105,10237-10245$.

(11) Zemski, K. A.; Justes, D. R.; Castleman, A. W., Jr. J. Phys. Chem. B 2002 $105,6136-6148$.

(12) Sambrano, J. R.; Andrés, J.; Beltrán, A.; Sensato, F.; Longo, E. Chem. Phys. Lett. 1998, 287, 620-626. 
DFT calculations to yield structural information on metal clusters with only a few additional oxygen atoms ${ }^{13-17}$ (those might be better named metal cluster oxides rather than oxide clusters). In addition to the electronic structure, vibrationally resolved PES can also provide vibrational frequencies. ${ }^{16}$ The limiting factor for the application of the ultraviolet PES technique to transition metal oxide clusters is the electron binding energy, which is usually very high for oxides with high oxidation states of the metal. A better basis to unravel the oxide cluster geometric structure is provided by experimental IR spectra.

Using matrix isolation FT-IR spectroscopy, the IR absorptions of several small niobium (and tantalum) oxide clusters up to $\mathrm{Nb}_{2} \mathrm{O}_{2}$ have been measured by Zhou and Andrews ${ }^{18}$ and assigned via oxygen isotopic substitution and by performing DFT calculations. From their vibrational properties also cationic $\left(\mathrm{NbO}^{+}, \mathrm{NbO}_{2}{ }^{+}\right)$and anionic $\left(\mathrm{NbO}_{2}{ }^{-}, \mathrm{NbO}_{3}{ }^{-}\right)$niobium oxide species have been identified in the argon matrix. Some of the unassigned bands increase in intensity during annealing, which might indicate that further aggregation occurs. Possibly larger clusters are also present in the matrix but cannot be identified.

In recent attempts in our laboratory, vibrational spectra of magnesium and zirconium oxide clusters have been obtained via IR resonance enhanced multiple photon ionization (IRREMPI). ${ }^{19,20}$ The principle of IR-REMPI spectroscopy requires that the cluster of interest has an ionization potential (IP) that is lower than its barrier for fragmentation, and therefore, this method is not applicable to oxides containing a transition metal in high formal oxidation states. These clusters usually have IPs $\gtrsim 10 \mathrm{eV}$, e.g., $9.5 \pm 1 \mathrm{eV}$ for $\mathrm{Nb}_{4} \mathrm{O}_{10},{ }^{21}$ whereas CID (of cluster ions) reveals fragmentation already at much lower collision energy (5.3 eV center-of-mass energy for $\mathrm{Nb}_{4} \mathrm{O}_{10}{ }^{+}$and $\mathrm{Kr}$ ). ${ }^{8}$ Asmis et al. have shown that IR multiple photon absorption induced fragmentation of vanadium oxide cluster cations $\mathrm{V}_{4} \mathrm{O}_{10}{ }^{+}$ in an ion trap is feasible and provides its IR spectrum in agreement with the theoretical prediction ${ }^{22}$ as well as the corresponding fragmentation channels. ${ }^{23}$

In this article we will show that IR multiple photon dissociation (IR-MPD) of oxide clusters is also possible in a free molecular beam, and we present the first infrared spectra of gas phase niobium oxide cluster cations. It will be shown that the cluster structures can be obtained on the basis of these spectra from comparison to harmonic frequencies calculated for possible isomers by DFT methods.

\section{Experimental Section}

The experiment is performed in a two-stage molecular beam setup containing a laser vaporization cluster source and a time-of-flight mass spectrometer. ${ }^{19,20}$ A scheme of the setup is shown in Figure 1. Gas

(13) Wang, L.-S.; Wu, H.; Desai, S. R. Phys. Rev. Lett. 1996, 76, 4853-4856.

(14) Wu, H.; Li, X.; Wang, X.-B.; Ding, C.-F.; Wang, L.-S. J. Chem. Phys. 1998, 109, 449-458.

(15) Klingeler, R.; Lüttgens, G.; Pontius, N.; Rochow, R.; Bechthold, P. S.; Neeb, M.; Eberhardt, W. Eur. Phys. J. D 1999, 9, 263-267.

(16) Green, S. M. E.; Alex, S.; Fleischer, N. L.; Millam, E. L.; Marcy, T. P.; Leopold, D. G. J. Chem. Phys. 2001, 114, 2653-2668.

(17) Pramann, A.; Koyasu, K.; Nakajima, A.; Kaya, K. J. Phys. Chem. A 2002 $106,4891-4896$.

(18) Zhou, M.; Andrews, L. J. Phys. Chem. A 1998, 102, 8251-8260.

(19) von Helden, G.; Kirilyuk, A.; van Heijnsbergen, D.; Sartakov, B.; Duncan, M. A.; Meijer, G. Chem. Phys. 2000, 262, 31-39.

(20) van Heijnsbergen, D.; von Helden, G.; Meijer, G.; Duncan, M. A. J. Chem Phys. 2002, 116, 2400-2406.

(21) Balducci, G.; Gigli, G.; Guido, M. J. Chem. Phys. 1986, 85, 5955-5960.

(22) Vyboishchikov, S. F.; Sauer, J. J. Phys. Chem. A 2001, 105, 8588-8598.

(23) Asmis, K. R.; Brümmer, M.; Kaposta, C.; Santambrogio, G.; von Helden, G.; Meijer, G.; Rademann, K.; Wöste, L. Phys. Chem. Chem. Phys. 2002, $4,1101-1104$.

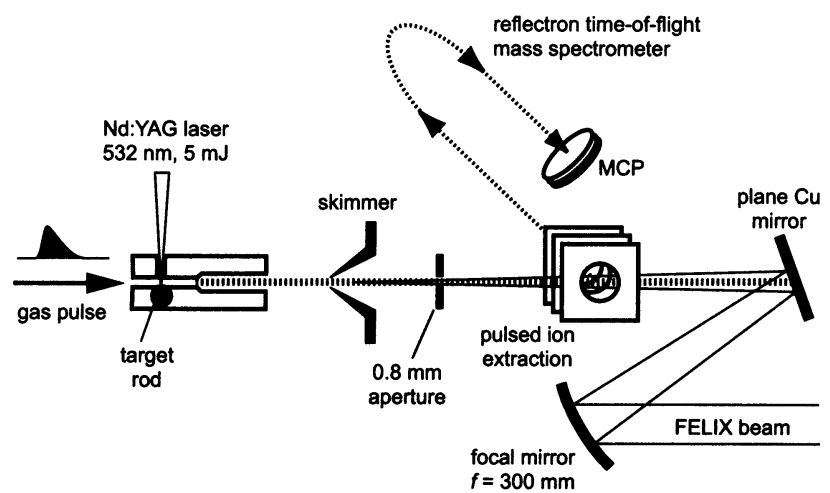

Figure 1. Scheme of the infrared multiple photon depletion experiment. The dashed lines indicate the pathway of the cluster ion beam. The plates of the reflectron time-of-flight mass spectrometer and additional steering plates are not shown.

phase niobium oxide clusters are produced in a standard laser vaporization source. The second-harmonic output of a Nd:YAG (Spectra-Physics GCR 150, typ. $5 \mathrm{~mJ} / \mathrm{pulse}$ ) laser is focused on a rotating and translating niobium rod (99.8\%, Aldrich Chem. Co.). Material is ablated forming a plasma and flushed with a short gas pulse of 0.25 oxygen in helium supplied by a current-loop actuated pulsed valve (R. M. Jordan Company, Inc.). Neutral and charged metal oxide clusters are formed and flow through a channel of $3 \mathrm{~mm}$ diameter that widens after $25 \mathrm{~mm}$ to $5 \mathrm{~mm}$ inner diameter. After a total pathway of $60 \mathrm{~mm}$ in the source channel that allows for thermalization of the clusters, the gas pulse expands into vacuum. After the beam is skimmed it is additionally shaped by a $0.8 \mathrm{~mm}$ aperture. The distribution of the cluster ions that are directly emitted from the source is analyzed with a perpendicularly extracting reflectron time-of-flight mass spectrometer (R. M. Jordan Company, Inc.).

The cluster beam overlaps longitudinally with a pulsed focused beam of infrared radiation produced by the Free Electron Laser for Infrared eXperiments (FELIX). ${ }^{24}$ The IR light comes in macropulses that are 7 $\mu$ s long and consists of $0.3-5$ ps duration micropulses spaced by $1 \mathrm{~ns}$. The energy of the macropulse is typically $50 \mathrm{~mJ}$, and the spectral width is set to $0.3 \%$ (rms) of the wavelength. The IR beam is focused with a spherical mirror of $300 \mathrm{~mm}$ focal length and steered with a flat mirror that is mounted on the axis of the molecular beam. The focus of the IR laser beam is located near the skimmer, ca. $3 \mathrm{~cm}$ upstream from the aperture.

When FELIX is resonant with an IR-allowed vibrational mode of a cluster, multiple absorption of single photons can take place. This process is facilitated by the high density of vibrational states and the fast internal vibrational redistribution (IVR) of vibrational energy in the cluster. The energy absorbed in an IR-active mode is thus very quickly transferred to the heat bath of other modes and the subsequent absorption of another photon is not hindered by anharmonicities. At high excitation (cross-) anharmonicities will however play a role and possibly limit the number of absorbed photons. For fullerenes, this absorption process has been modeled and the experiment and model indicate that the absorption of more than 500 photons by a single molecule in a single macropulse is realistic. ${ }^{25}$ The principles of IR multiple photon absorption by binary metal compound clusters (carbides and oxides) are discussed in detail elsewhere. ${ }^{26}$

If the cluster gains enough energy to overcome its barrier for dissociation, cluster fragmentation becomes possible, leading to intensity changes in the mass spectrum. Since the dissociation energies of oxide clusters are typically on the order of at least $1-2 \mathrm{eV}$, many IR photons,

(24) Oepts, D.; van der Meer, A. F. G.; van Amersfoort, P. W. Infrared Phys. Technol. 1995, 36, 297-308.

(25) von Helden, G.; Hollemann, I.; Meijer, G.; Sartakov, B. Opt. Express 1999 , $4,46-52$.

(26) von Helden, G.; van Heijnsbergen, D.; Meijer, G. J. Phys. Chem. A (in press). 
Table 1. Calculated Properties for Mononuclear Niobium Oxide Species, Including the Oxotrichloride Molecule, and for Oxygen at the DFT (B3LYP/LACVP*) Level and Comparison to Experimental Data

\begin{tabular}{lcccc}
\hline & exptl & ref & calcd & scaled \\
\hline $\mathrm{NbO}$ & & & & \\
$d(\mathrm{Nb}-\mathrm{O})$ & $1.691 \AA$ & {$[28]$} & $1.702 \AA$ & \\
$v$ & $989 \mathrm{~cm}^{-1}$ & {$[28]$} & $1033 \mathrm{~cm}^{-1}$ & $990 \mathrm{~cm}^{-1}$ \\
$\mathrm{NbO}^{+}$ & & & & \\
$d(\mathrm{Nb}-\mathrm{O})$ & & & $1.675 \AA$ & \\
$v$ & $1000 \mathrm{~cm}^{-1}$ & {$[18]$} & $1066 \mathrm{~cm}^{-1}$ & $1021 \mathrm{~cm}^{-1}$ \\
$\mathrm{NbO}_{2}{ }^{+}$ & & & & \\
$d(\mathrm{Nb}-\mathrm{O})$ & & & $1.697 \AA$ & \\
$\angle(\mathrm{O}-\mathrm{Nb}-\mathrm{O})$ & & & $102.8^{\circ}$ & \\
$v_{1}$ & $989 \mathrm{~cm}^{-1}$ & {$[18]$} & $1059 \mathrm{~cm}^{-1}$ & $1015 \mathrm{~cm}^{-1}$ \\
$v_{3}$ & $938 \mathrm{~cm}^{-1}$ & {$[18]$} & $1015 \mathrm{~cm}^{-1}$ & $973 \mathrm{~cm}^{-1}$ \\
$\mathrm{NbOCl}$ & & & & \\
$d(\mathrm{Nb}-\mathrm{O})$ & & & $1.706 \AA$ & \\
$v(\mathrm{Nb}-\mathrm{O})$ & $997 \mathrm{~cm}^{-1}$ & {$[29]$} & $1031 \mathrm{~cm}^{-1}$ & $988 \mathrm{~cm}^{-1}$ \\
$v(\mathrm{Nb}-\mathrm{Cl}$ asym. $)$ & $448 \mathrm{~cm}^{-1}$ & {$[29]$} & $446 \mathrm{~cm}^{-1}$ & $437 \mathrm{~cm}^{-1}$ \\
$v(\mathrm{Nb}-\mathrm{Cl}$ sym. $)$ & $395 \mathrm{~cm}^{-1}$ & {$[29]$} & $413 \mathrm{~cm}^{-1}$ & $405 \mathrm{~cm}^{-1}$ \\
$\mathrm{O}_{2}{ }^{3} \Sigma_{\mathrm{g}}{ }^{-}$ & & & & \\
$d(\mathrm{O}-\mathrm{O})$ & $1.208 \AA$ & {$[28]$} & $1.214 \AA$ & \\
$v(\mathrm{O}-\mathrm{O})$ & $1580 \mathrm{~cm}^{-1}$ & {$[28]$} & $1658 \mathrm{~cm}^{-1}$ & $1579 \mathrm{~cm}^{-1}$ \\
& & & & \\
\hline
\end{tabular}

e.g., $8-16$ photons at $10 \mu \mathrm{m}$, have to be absorbed per cluster at a minimum. The timing of the cluster source relative to the IR macropulse is optimized for maximum depletion of the cluster signals. The mass spectra are averaged and recorded as a function of FELIX wavelength using a digital oscilloscope that is connected to a personal computer.

\section{Computational Details}

The geometry optimization for selected clusters is performed with the Jaguar $4.0^{27}$ program using the B3LYP functional and the LACVP* basis set $(6-31 \mathrm{G}$ for $\mathrm{O}$; Hay-Wadt VDZ $(n+1)$ ECP basis for $\mathrm{Nb})$. The harmonic vibrational frequencies and the corresponding IR intensities are computed numerically. The reliability of this method is tested by comparison with experimental data for $\mathrm{NbO}, \mathrm{NbO}^{+}, \mathrm{NbO}_{2}{ }^{+}$, $\mathrm{NbOCl}_{3}$, and $\mathrm{O}_{2}$ (Table 1). For $\mathrm{NbO}$ we find a quartet ground state, while for $\mathrm{NbO}^{+}$the triplet state is found to be the lowest. In general, the calculated vibration frequencies are higher than the experimental values, but this is consistent with the known performance of the B3LYP functional. The recommended scaling factor of about $0.96^{30}$ leads to better agreement between calculation and experimental observation. To obtain better agreement also for the lower frequency modes, this scaling factor is varied and an offset is additionally introduced, resulting in the optimum scaling formula:

$$
\bar{v}=16 \mathrm{~cm}^{-1}+\bar{v}(\text { calc }) \times 0.943
$$

derived by fitting the calculated frequencies to the experimental values given in Table 1 (without using the data from matrix isolation spectroscopy).

Dissociation energies are calculated from the differences of the total energies of the reactands without any further adjustments.

\section{Results}

4.1. Cluster Composition. A typical mass spectrum of the cationic oxide cluster distribution is shown in Figure 2. The cluster formation conditions are optimized to yield small clusters

(27) Jaguar 4.0; Schrödinger, Inc.: Portland, OR, 1991-2000.

(28) Huber, K. P.; Herzberg, G. Constants of Diatomic Molecules (data prepared by J. W. Gallagher and R. D. Johnson, III). In NIST Chemistry WebBook, NIST Standard Reference Database Number 69; Linstrom, P. J., Mallard, W. G., Eds.; National Institute of Standards and Technology: Gaithersburg, MD, 20899, July 2001 (http://webbook.nist.gov)

(29) Rosenkilde, C.; Voyiatzkis, G.; Jensen, V. R.; Ystenes, M.; Østvold, T. Inorg. Chem. 1995, 34, 4360-4369.

(30) Scott, A. P.; Radom, L. J. Phys. Chem. 1996, 100, 16502-16513.

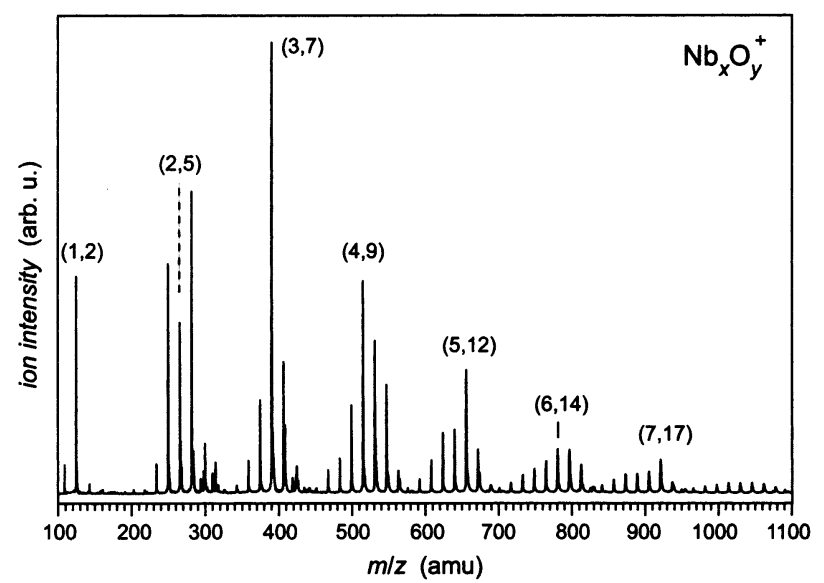

Figure 2. Mass spectrum of niobium oxide cluster cations, emitted directly from the laser vaporization source. The composition of the oxide clusters is given in the form of $(x, y)$.

with less than 10 niobium atoms in high intensity. The distribution contains mainly niobium oxide clusters with $\mathrm{Nb} / \mathrm{O}$ ratios from 1 to slightly above 2.5 , corresponding to a formal oxidation state of niobium between +2 and +5 . The composition of pure niobium oxide clusters never exceeds the stoichiometries $\left(\mathrm{Nb}_{2} \mathrm{O}_{5}\right)_{n} \mathrm{O}^{+}$or $\left(\mathrm{Nb}_{2} \mathrm{O}_{5}\right)_{n} \mathrm{NbO}_{3}{ }^{+}$. The presence of clusters having one oxygen atom more than necessary to fulfill the +5 oxidation state of niobium indicates the presence of peroxidic species or molecular oxygen adsorbates. Peaks that might be assigned to even higher oxide clusters have been identified to be hydroxylated or hydrated species, but those are not the subject of discussion here.

4.2. Depletion Spectra. Figures 3 and 4 show the relative intensity changes for selected oxide cluster cations that occur while scanning the IR frequency. The spectra are measured in the range of $400-1650 \mathrm{~cm}^{-1}$, but only the $500-1400 \mathrm{~cm}^{-1}$ region is shown, as the cluster distribution was not influenced by FELIX when being outside this range.

In the spectra, dips and/or intensity increases can be observed and several spectral features can be identified. Dips occur when a cluster fragments upon IR irradiation. Increases occur when heavier clusters fragment and the fragmentation products end up at the mass monitored. For most clusters shown a narrow band is found around $990 \mathrm{~cm}^{-1}$ and broader bands in the 700$900 \mathrm{~cm}^{-1}$ range. For no clusters, except for $\mathrm{Nb}_{2} \mathrm{O}_{6}{ }^{+}$, can bands below $700 \mathrm{~cm}^{-1}$ be identified unequivocally. Also above 1000 $\mathrm{cm}^{-1}$ no peaks are observed.

For a cluster group with a fixed number of niobium atoms, the intensity of oxide clusters with rather low oxygen content remains nearly unchanged over the whole spectrum, while for the clusters with the highest oxygen content (e.g., $\mathrm{Nb}_{3} \mathrm{O}_{8}{ }^{+}$or $\mathrm{Nb}_{4} \mathrm{O}_{11}{ }^{+}$) strong depletion at distinct frequencies is observed. For clusters with an intermediate oxygen content (e.g., for $\mathrm{Nb}_{5} \mathrm{O}_{12}{ }^{+}$) the two effects, depletion and intensity growth due to fragmentation of larger clusters, are observed to occur. In those spectra, the depletion band around $990 \mathrm{~cm}^{-1}$ is observed to occur on the red side of the growth band. This observation indicates that absorption frequencies are cluster size dependent and that for this band a blue shift with increasing cluster size and/or increasing oxygen content occurs.

The oxide cluster with the highest intensity in the mass spectrum, $\mathrm{Nb}_{3} \mathrm{O}_{7}{ }^{+}$, exhibits a special behavior. No depletion is observed at all, and its absolute intensity growth is much larger 


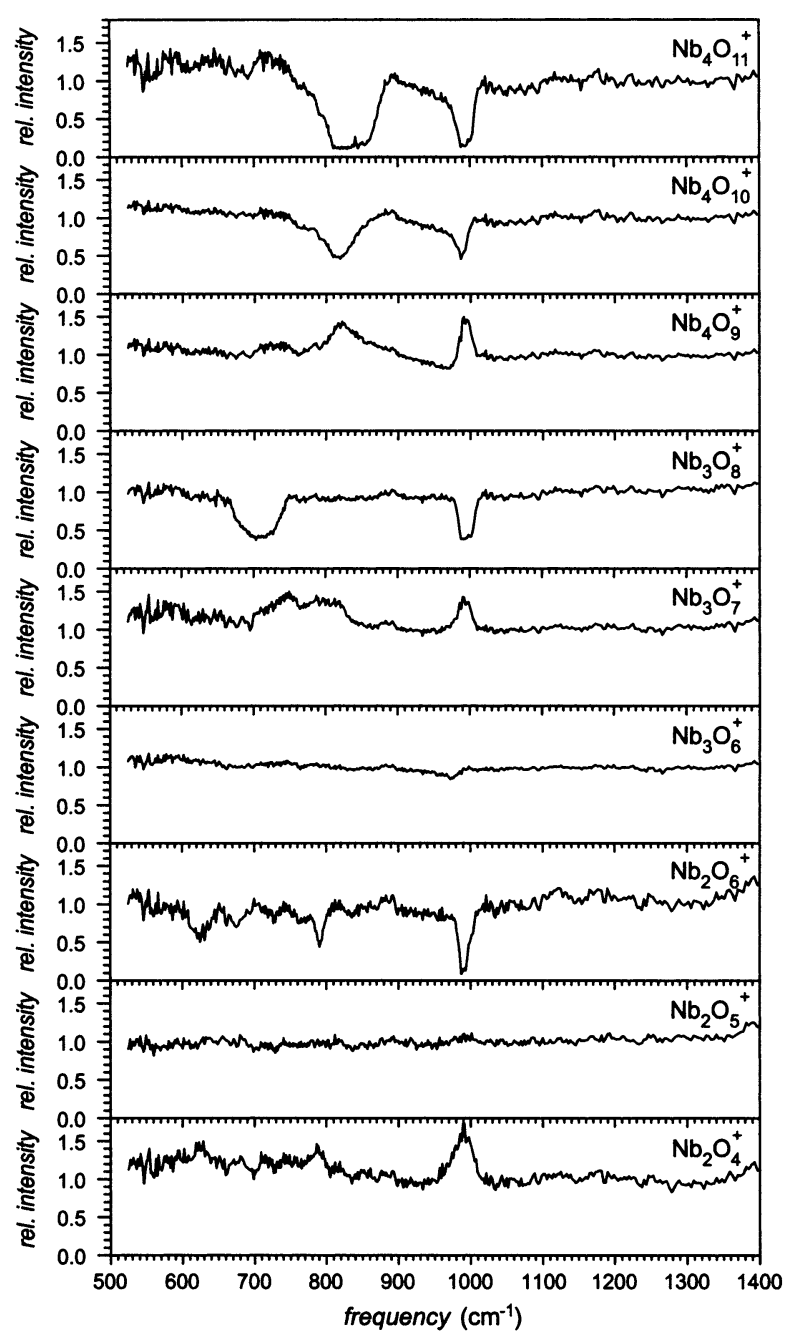

Figure 3. Relative ion intensity as function of IR frequency for selected oxide cluster cations containing $2-4$ niobium atoms. The ion intensity is normalized to the intensity in the $1100-1400 \mathrm{~cm}^{-1}$ range, where no IR laser induced fragmentation signals are observed. Intensity decrease below 1 corresponds to fragmentation of that ion, whereas an increase is due to formation of that ion during fragmentation of larger cluster ions.

than for any other cluster. This might indicate that $\mathrm{Nb}_{3} \mathrm{O}_{7}{ }^{+}$is a favored fragment for larger clusters. This points to a special stability of the stoichiometric and closed shell cluster $\mathrm{Nb}_{3} \mathrm{O}_{7}{ }^{+}$, which would also explain its high intensity in the mass spectrum.

\section{Discussion}

5.1. $\mathrm{Nb}_{2} \mathrm{O}_{6}{ }^{+}$. 5.1.1. Isomeric Structures. The optimized geometries and relative energies of the isomers of $\mathrm{Nb}_{2} \mathrm{O}_{6}{ }^{+}$are shown in Figure 5a. In these clusters different oxygen species can be identified ranging from terminal (double bonded) and bridging oxo $\left(\mathrm{O}^{2-}\right)$ groups to different superoxo $\left(\eta^{1}-\mathrm{O}_{2}{ }^{-}\right.$in Ia and Ib) and peroxo $\left(\mu^{2}-\mathrm{O}_{2}{ }^{2-}\right.$ in II; $\eta^{2}-\mathrm{O}_{2}{ }^{2-}$ in III) species. Triple $-\mathrm{O}-$ bridged starting configurations did not preserve this structural element during optimization, but converged to II. Ozonide-containing structures have not been considered, since they are expected to be much higher in energy.

The two most stable isomers Ia and Ib contain a $\eta^{1}$-bonded superoxo group and two terminal oxo groups. In the slightly more stable isomer Ia the oxo groups are in the trans configuration, while they are in the cis configuration in Ib. Their ground state is a doublet, and Mulliken analysis of atomic spin

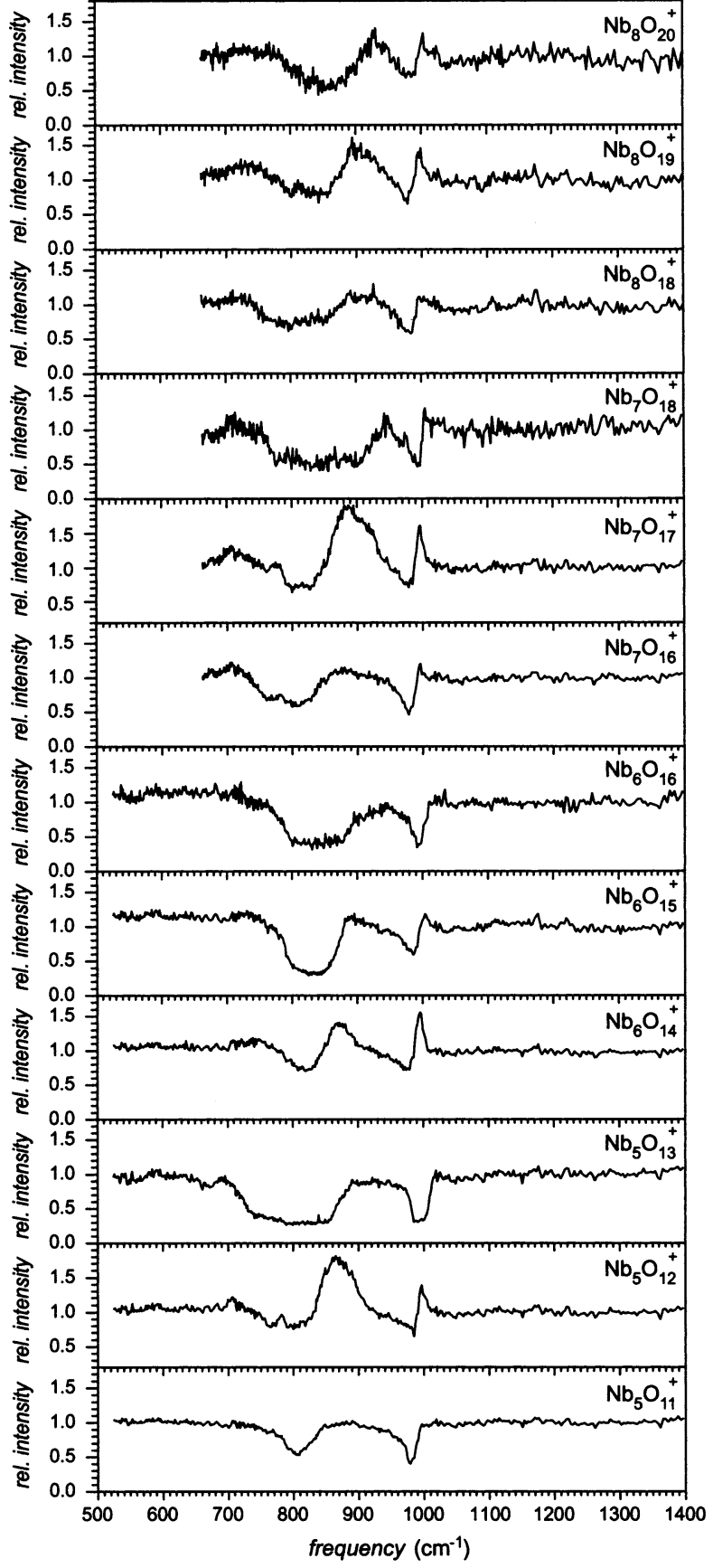

Figure 4. Ion intensity as a function of IR frequency for selected oxide cluster cations containing 5-8 niobium atoms. The spectrum below 700 $\mathrm{cm}^{-1}$ is not measured for the larger clusters.

densities reveals that the unpaired electron is distributed between the oxygen atoms of the superoxide group with maximum density $(75 \%)$ at the terminal atom. For the vanadium homologue $\mathrm{V}_{2} \mathrm{O}_{6}{ }^{+}$it has been proposed by Calatayud et al. ${ }^{31}$ that the most stable isomer resembles the cis form $\mathbf{I b}$, but it is actually unclear if the trans arrangement has been considered. Peroxo groups (in II and III) seem to be unfavorable, since these isomers are nearly $1 \mathrm{eV}$ higher in energy. A cluster having only one bridging $\mathrm{O}$ atom (III) is much higher in energy.

5.1.2. IR Spectra. In Figure 6 the calculated infrared spectra of the five isomers of $\mathrm{Nb}_{2} \mathrm{O}_{6}{ }^{+}$are compared to the experimental

(31) Calatayud, M.; Andrés, J.; Beltrán, A. J. Phys. Chem. A 2001, 105, 97609775 . 

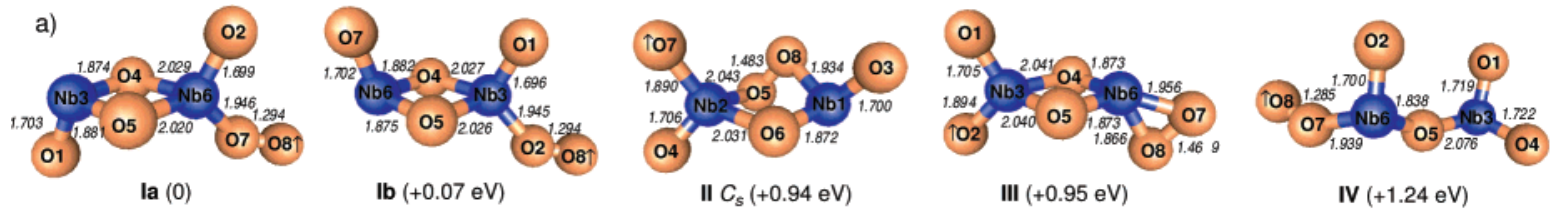

lb $(+0.07 \mathrm{eV}$

III $(+0.95 \mathrm{eV})$

IV $(+1.24 \mathrm{eV})$

b)
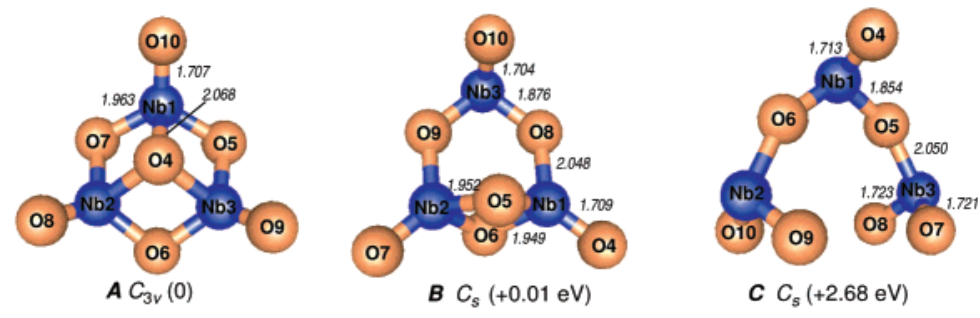

c)
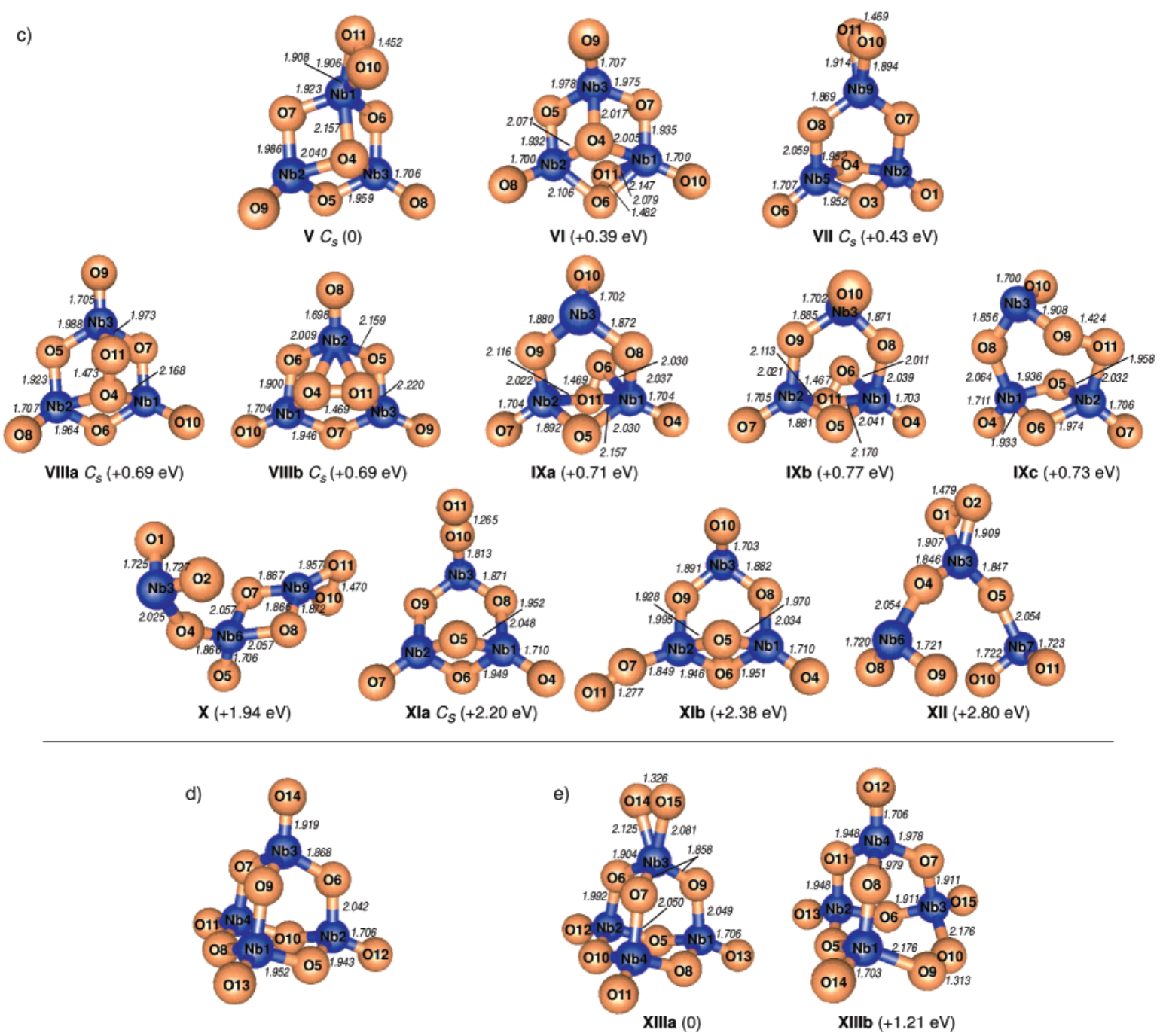

Figure 5. Optimized geometric structures of isomers of niobium oxide cluster cations. From top to bottom: (a) $\mathrm{Nb}_{2} \mathrm{O}_{6}^{+}$; (b) $\mathrm{Nb}_{3} \mathrm{O}_{7}^{+}$; (c) $\mathrm{Nb}_{3} \mathrm{O}_{8}{ }^{+}$; (d) $\mathrm{Nb}_{4} \mathrm{O}_{10}{ }^{+}$; and (e) $\mathrm{Nb}_{4} \mathrm{O}_{11}{ }^{+}$. The point group is only given if it is not $C_{1}$. The bond lengths are in $\AA$.

spectrum. In the measured spectrum bands at $625,675,790$, and $990 \mathrm{~cm}^{-1}$ can be clearly identified. The calculated spectra for the isomers Ia and Ib are, as expected, very similar. The analysis of the vibrational modes reveals that the doublets at 998 and $1007 \mathrm{~cm}^{-1}$ (Ia) as well as 997 and $1013 \mathrm{~cm}^{-1}$ (Ib) belong to the symmetric and antisymmetric stretches of the two terminal $\mathrm{Nb}=\mathrm{O}$ groups. The stretch vibration of the superoxide $\eta^{1}-\mathrm{O}_{2}{ }^{-}$is found at $\sim 1145 \mathrm{~cm}^{-1}$, a value that falls nicely in the
$1100-1150 \mathrm{~cm}^{-1}$ range of absorption frequencies for known $\eta^{1}-\mathrm{O}_{2}{ }^{-}$transition metal complexes. ${ }^{32}$ For both isomers Ia and Ib, the bands at $\sim 534 \mathrm{~cm}^{-1}$ represent the stretch of the $\eta^{1}-\mathrm{O}_{2}{ }^{-}$ group against the $\mathrm{Nb}$ atom and the absorptions at $\sim 616, \sim 660$, and $\sim 775 \mathrm{~cm}^{-1}$ can be assigned to in-plane vibrations of the two bridging $\mathrm{O}$ atoms.

(32) Sheppard, N. In Vibrational Spectroscopy of Adsorbates; Willis, R. F., Ed.; Springer-Verlag: Berlin, 1980; pp 165-176. 

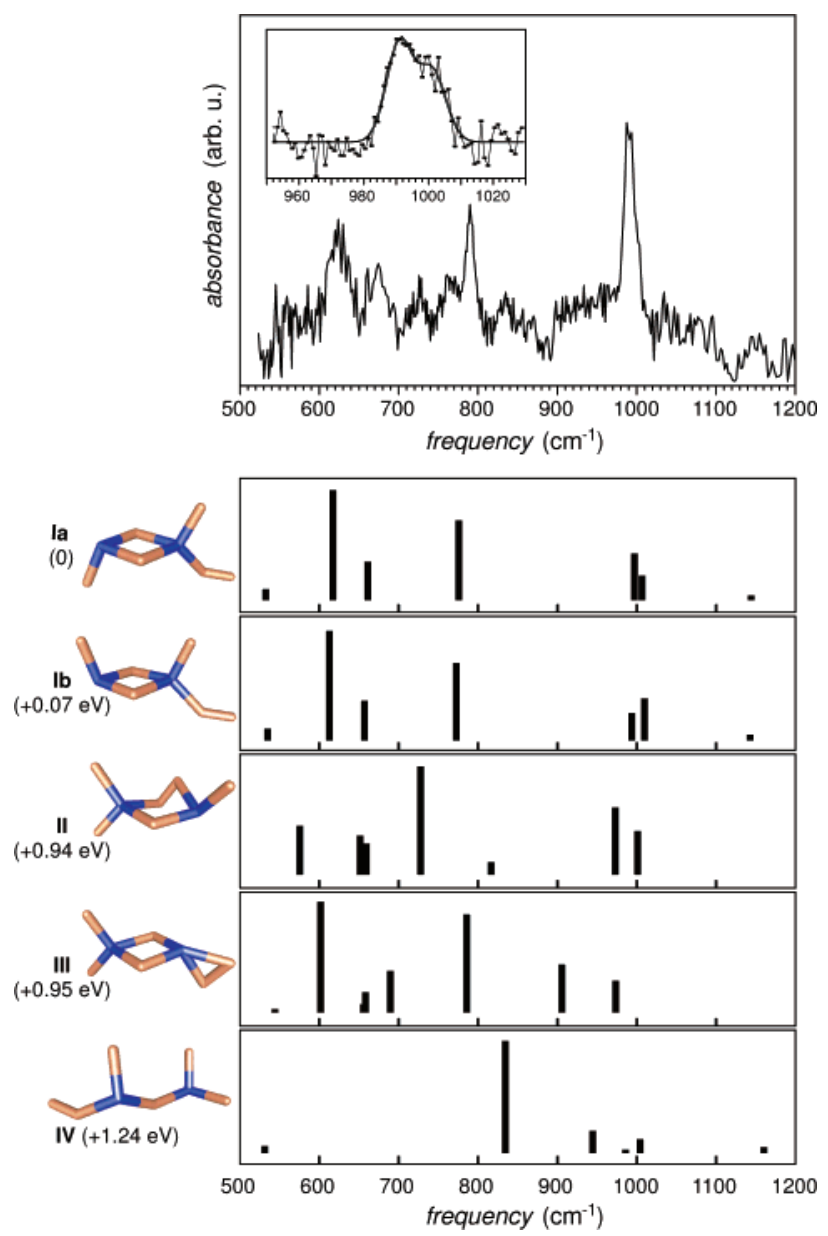

Figure 6. Top: Experimental IR spectrum of $\mathrm{Nb}_{2} \mathrm{O}_{6}{ }^{+}$as obtained by IR multiple photon depletion spectroscopy. The inset shows the band around $990 \mathrm{~cm}^{-1}$ with higher resolution. The fitted line is the envelope of two separate peaks at 989 and $999 \mathrm{~cm}^{-1}\left(10 \mathrm{~cm}^{-1} \mathrm{fwhm}\right)$. Bottom: Calculated IR spectra for five different isomers, whose geometric structure is schematically indicated on the left-hand side.

In isomer II the internal stretch of the peroxo unit is found at $818 \mathrm{~cm}^{-1}$ and the terminal oxo groups have vibrational frequencies of $975,1003(\mathrm{Nb}=\mathrm{O})$, and $661 \mathrm{~cm}^{-1}\left(\mathrm{Nb}^{(2)}-\mathrm{O}^{(7)}\right)$. The remaining modes correspond to vibration modes of the ring. For isomer III the $\mathrm{O}-\mathrm{O}$ stretch of the $\eta^{2}-\mathrm{O}_{2}{ }^{2-}$ ligand is excited at $907 \mathrm{~cm}^{-1}$. The two lines around $695 \mathrm{~cm}^{-1}$ correspond to synchronous symmetric and antisymmetric $\mathrm{Nb}-\mathrm{O}$ stretchings of the single-bonded terminal $\mathrm{O}^{(2)}$ and the $\eta^{2}-\mathrm{O}_{2}{ }^{2-}$ ligand. All other vibrations are analogous to those in Ia and Ib. The strongest IR line of isomer IV at $835 \mathrm{~cm}^{-1}$ corresponds to antisymmetric stretching of the $\mathrm{Nb}-\mathrm{O}-\mathrm{Nb}$ bridge. The 945 $\mathrm{cm}^{-1}$ band is assigned to the antisymmetric stretch of the niobium dioxo $\mathrm{Nb}^{(3)} \mathrm{O}^{(1)} \mathrm{O}^{(4)}$ group.

The experimental IR spectrum of $\mathrm{Nb}_{2} \mathrm{O}_{6}{ }^{+}$agrees well with either one of the calculated spectra of the two isomers Ia and Ib. For a detailed comparison, the bands in the $\mathrm{Nb}=\mathrm{O}$ stretch region around $1000 \mathrm{~cm}^{-1}$ have to be taken into account. The inset in Figure 6 shows an expanded view of this region. The experimental band consists of two overlapping peaks at 989 and $999 \mathrm{~cm}^{-1}$. Although the calculated frequencies for both isomers are shifted compared to the experiment, the splitting of $10 \mathrm{~cm}^{-1}$ between the experimental peaks matches better with the $9 \mathrm{~cm}^{-1}$ splitting in Ia than with the $16 \mathrm{~cm}^{-1}$ splitting in Ib. We can thus conclude that the $\mathrm{Nb}_{2} \mathrm{O}_{6}{ }^{+}$isomer that is experi- mentally observed has the structure Ia, which also corresponds to the energetically lowest of all computed isomers.

5.1.3. Dissociation Pathway. $\mathrm{Nb}_{2} \mathrm{O}_{4}{ }^{+}$is the only cluster smaller than $\mathrm{Nb}_{2} \mathrm{O}_{6}{ }^{+}$that shows intensity increases at some wavelengths (Figure 3, bottom trace). This increase is correlated to the dips in the $\mathrm{Nb}_{2} \mathrm{O}_{6}{ }^{+}$ion signal, and it thus seems reasonable that $\mathrm{Nb}_{2} \mathrm{O}_{6}{ }^{+}$fragments by losing molecular oxygen. This dissociation channel is in agreement with the observed loss of $\mathrm{O}_{2}$ after collisions of $\mathrm{Nb}_{2} \mathrm{O}_{6}{ }^{+}$with hydrocarbons.9,10 The calculated dissociation energy of isomer Ia is $1.3 \mathrm{eV}$;

$$
\mathrm{Nb}_{2} \mathrm{O}_{6}^{+} \rightarrow \mathrm{Nb}_{2} \mathrm{O}_{4}^{+}+\mathrm{O}_{2} \quad \Delta E=+1.30 \mathrm{eV}
$$

The structure of the fragment $\mathrm{Nb}_{2} \mathrm{O}_{4}{ }^{+}$is obtained by removing the $\eta^{1}-\mathrm{O}_{2}{ }^{-}$unit from $\mathbf{I a}$ and allowing for relaxation. The ground state of this trans isomer of $\mathrm{Nb}_{2} \mathrm{O}_{4}{ }^{+}$is a doublet. The corresponding cis isomer is calculated to be $0.12 \mathrm{eV}$ higher in energy.

5.2. $\mathrm{Nb}_{3} \mathrm{O}_{8}{ }^{+}$. 5.2.1. Isomeric Structures. The cluster $\mathrm{Nb}_{3} \mathrm{O}_{8}{ }^{+}$ contains one additional oxygen atom when compared to the stoichiometric composition of $\left(\mathrm{Nb}_{2} \mathrm{O}_{5}\right) \mathrm{NbO}_{2}{ }^{+}$with all $\mathrm{Nb}$ atoms in a formal +5 oxidation state. Therefore, the number of isomers for the oxygen-rich cluster $\mathrm{Nb}_{3} \mathrm{O}_{8}{ }^{+}$is expected to be much higher than for the corresponding stoichiometric cluster $\mathrm{Nb}_{3} \mathrm{O}_{7}{ }^{+}$. The geometries of various isomers of $\mathrm{Nb}_{3} \mathrm{O}_{8}{ }^{+}$are derived by adding oxygen atoms to the three basic isomeric structures of $\mathrm{Nb}_{3} \mathrm{O}_{7}{ }^{+}$shown in Figure 5b. The two cage-like isomers $\boldsymbol{A}$ and $\boldsymbol{B}$ are very close in energy, while the tree-like isomer $\boldsymbol{C}$ is 2.68 $\mathrm{eV}$ higher in energy. $\boldsymbol{A}$ is unique among the niobium oxide cluster isomers found, not only because of its high $C_{3 v}$ symmetry but also because of the presence of a 3 -fold coordinated $\mathrm{O}$ atom in the center of the cluster. $\boldsymbol{B}$ consists of a double $-\mathrm{O}-$ bridged subunit as in the $\mathrm{Nb}_{2} \mathrm{O}_{6}{ }^{+}$isomer $\mathbf{I b}$, which is capped by $\mathrm{NbO}_{3}$. The mean coordination number of the niobium atoms in these isomers is four or close to four. In isomer $\boldsymbol{C}$ the mean coordination number is only three, which might explain its reduced stability.

The most stable isomer $\mathbf{V}$ of $\mathrm{Nb}_{3} \mathrm{O}_{8}{ }^{+}$consists of a $\eta^{2}-\mathrm{O}_{2}{ }^{2-}$ unit attached to the nearly $C_{3 v}$ symmetric core of $\boldsymbol{A}$. The replacement of an $>\mathrm{O}$ bridge in $\boldsymbol{A}$ by $>\mathrm{O}=\mathrm{O}$ leads to isomer VI, which is $0.39 \mathrm{eV}$ higher in energy. The other isomers derived from $\boldsymbol{A}$ are less stable and contain $\mu^{3}-\mathrm{O}_{2}{ }^{2-}$ (VIIIa,b). The $\mu^{2}\left(\eta^{1}: \eta^{2}\right)-\mathrm{O}_{2}{ }^{2-}$ unit bridges $\mathrm{Nb}^{(1)}$ and $\mathrm{Nb}^{(1)}$ asymmetrically, having different distances for $d\left(\mathrm{O}^{(11)}-\mathrm{Nb}^{(1)}\right)$ and $d\left(\mathrm{O}^{(11)}-\mathrm{Nb}^{(2)}\right)$ of 2.147 and $2.397 \AA$, respectively.

The cluster $\boldsymbol{B}$ forms the parent structure for the $\mathrm{Nb}_{3} \mathrm{O}_{8}{ }^{+}$ isomer VII. This isomer is less stable compared to $\mathbf{V}$ by 0.43 $\mathrm{eV}$ and also contains an $\eta^{2}-\mathrm{O}_{2}{ }^{2-}$ unit. Replacement of a $-\mathrm{O}-$ bridge in $\boldsymbol{B}$ by $-\mathrm{O}-\mathrm{O}-$ leads to $\mathbf{I X a}-\mathbf{c}$. The bonding of the $\mu^{2}\left(\eta^{1}: \eta^{2}\right)-\mathrm{O}_{2}{ }^{2-}$ unit in IXa,b is similar to the dioxo group in VI. The structures of additional isomers are shown in Figure 5c. Their energies are, however, more than $1 \mathrm{eV}$ higher than that of the most stable isomer $\mathbf{V}$. It is noted that the proposed structure for $\mathrm{Nb}_{3} \mathrm{O}_{8}{ }^{+}$in earlier works ${ }^{8,12}$ corresponds to the treelike isomer XII, which has an energy $2.8 \mathrm{eV}$ above that of the most stable isomer $\mathbf{V}$. From the calculated energetic properties of the isomers of $\mathrm{Nb}_{3} \mathrm{O}_{8}{ }^{+}$we conclude that, in general, compact cage-like structures are more stable than open structures $(\mathbf{X})$ or tree-like isomers (XII).

5.2.2. IR Spectra. A comparison between the experimental IR spectrum and calculated IR spectra for selected isomers of 

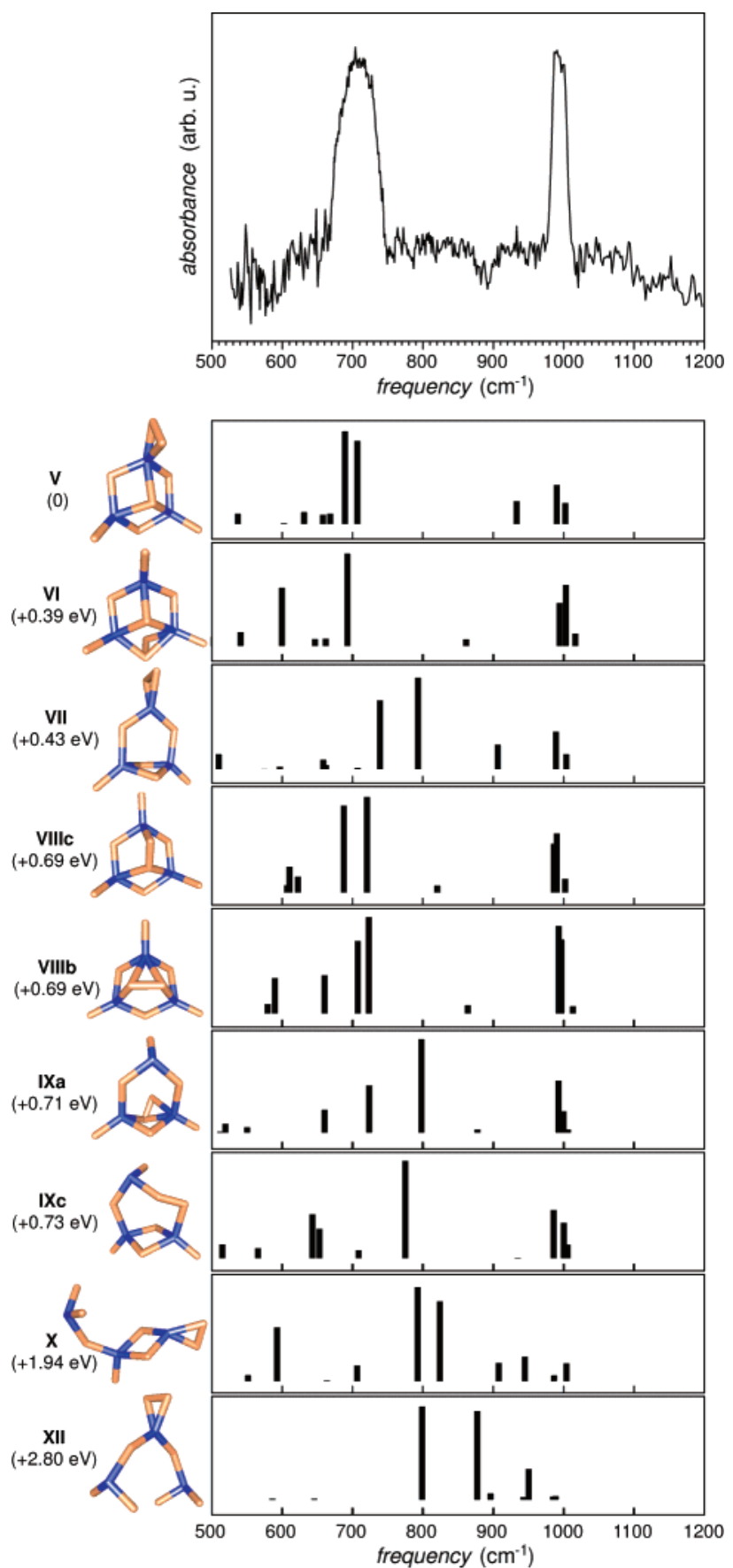

Figure 7. Experimental IR spectrum of $\mathrm{Nb}_{3} \mathrm{O}_{8}{ }^{+}$as obtained by IR multiple photon depletion spectroscopy (top) compared to the calculated IR spectra of nine possible isomers.

$\mathrm{Nb}_{3} \mathrm{O}_{8}{ }^{+}$is made in Figure 7. For most isomers the $\mathrm{Nb}=\mathrm{O}$ stretch frequencies are found around $1000 \mathrm{~cm}^{-1}$, whereas for terminal $\mathrm{NbO}_{2}$ groups as in $\mathbf{X}\left(\mathrm{Nb}^{(3)} \mathrm{O}^{(1)} \mathrm{O}^{(2)}\right)$ and $\mathbf{X I I}\left(\mathrm{Nb}^{(6)} \mathrm{O}^{(8)} \mathrm{O}^{(9)}\right.$ and $\left.\mathrm{Nb}^{(7)} \mathrm{O}^{(10)} \mathrm{O}^{(11)}\right)$ the symmetric stretch vibration is slightly redshifted to about $990 \mathrm{~cm}^{-1}$, while the antisymmetric stretch vibration is found at $950 \mathrm{~cm}^{-1}$. The $\mathrm{Nb}-\mathrm{O}$ stretch region covers a wide range of 500-880 $\mathrm{cm}^{-1}$. Characteristic for the $-\mathrm{O}-$ $\mathrm{Nb}-\mathrm{O}-$ bridge, e.g., in VII and IXa, are the symmetric and the antisymmetric stretch at 740 and $790 \mathrm{~cm}^{-1}$, respectively. The calculated stretch vibration frequencies of the various dioxo groups are as follows:

(i) $\mu^{3}-\mathrm{O}_{2}{ }^{2-}$ (in XIIIa,b) 822 and $864 \mathrm{~cm}^{-1}$,

(ii) $\mu^{2}\left(\eta^{1}: \eta^{2}\right)-\mathrm{O}_{2}{ }^{2-}$ (in VI, IXa,b) $861-878 \mathrm{~cm}^{-1}$, (iii) $\eta^{2}-\mathrm{O}_{2}{ }^{2-}$ (in $\left.\mathbf{V}, \mathbf{V I}, \mathbf{X}, \mathbf{X I I}\right) 878-934 \mathrm{~cm}^{-1}$ (increasing with decreasing $\mathrm{O}-\mathrm{O}$ bond length),

(iv) $\mu^{2}-\mathrm{O}_{2}{ }^{2-}$ (in IXc) $935 \mathrm{~cm}^{-1}$,

(v) $\eta^{1}-\mathrm{O}_{2}^{-}$(in XIa,b) 1302 and $1237 \mathrm{~cm}^{-1}$.

Best agreement between experimental and calculated IR spectrum is obtained for isomer $\mathbf{V}$. The symmetric stretch of the two equivalent $\mathrm{Nb}=\mathrm{O}$ groups is found at $1003 \mathrm{~cm}^{-1}$, whereas the antisymmetric stretch is at $991 \mathrm{~cm}^{-1}$. The two most intense bands correspond to concerted displacements of four $\mathrm{O}$ atoms, an antisymmetric stretch of the $\mathrm{O}$ tetrahedron around $\mathrm{Nb}^{(1)}\left(689 \mathrm{~cm}^{-1}\right)$, and a mode where all bridging $\mathrm{O}$ atoms move in phase relative to the $\mathrm{Nb}$ atoms and perpendicular to the symmetry plane $\left(707 \mathrm{~cm}^{-1}\right)$. However, the calculation predicts an internal stretch vibration of the $\eta^{2}-\mathrm{O}_{2}{ }^{2-}$ ligand to be at 934 $\mathrm{cm}^{-1}$ with an intensity that is comparable to the $\mathrm{Nb}=\mathrm{O}$ stretches. Such a mode can, however, not be identified in the experimental spectrum. The absence of this predicted absorption peak might be explained by ineffective coupling of the $\eta^{2}-\mathrm{O}_{2}{ }^{2-}$ stretch vibration to the cluster core, which would slow intramolecular vibrational energy redistribution (IVR). As a consequence, resonance-enhanced multiple photon absorption could be less efficient on this mode, making it difficult to detect this mode via IR-MPD.

5.2.3. Dissociation Pathway. To analyze the dissociation pathway of $\mathrm{Nb}_{3} \mathrm{O}_{8}{ }^{+}$, the intensity variations of the ion signal for the clusters with less oxygen content and with less niobium atoms have to be analyzed, to include channels with oxygen loss as well as cluster fission. The only cluster with two $\mathrm{Nb}$ atoms for which an intensity increase is observed is $\mathrm{Nb}_{2} \mathrm{O}_{4}{ }^{+}$. Fission of $\mathrm{Nb}_{3} \mathrm{O}_{8}{ }^{+}$under release of neutral $\left\{\mathrm{NbO}_{2}, \mathrm{O}_{2}\right\}$ fragments is rather unlikely from the energetic point of view, and, more important, no intensity increases are observed for $\mathrm{Nb}_{2} \mathrm{O}_{4}{ }^{+}$at the position of the $710 \mathrm{~cm}^{-1}$ absorption band of $\mathrm{Nb}_{3} \mathrm{O}_{8}{ }^{+}$. Release of an $\mathrm{O}_{2}$ molecule similar to the fragmentation behavior of $\mathrm{Nb}_{2} \mathrm{O}_{6}{ }^{+}$also does not occur, since the absolute intensity of $\mathrm{Nb}_{3} \mathrm{O}_{6}{ }^{+}$is comparable to that of $\mathrm{Nb}_{3} \mathrm{O}_{8}{ }^{+}$, but does not change during the IR scan. Hence, the remaining fragmentation channel is release of atomic $\mathrm{O}$ giving $\mathrm{Nb}_{3} \mathrm{O}_{7}{ }^{+}$, in agreement with the conclusion from CID experiments, ${ }^{8}$ i.e.,

$$
\mathrm{Nb}_{3} \mathrm{O}_{8}^{+} \rightarrow \mathrm{Nb}_{3} \mathrm{O}_{7}^{+}+\mathrm{O} \quad \Delta E=+2.56 \mathrm{eV}
$$

Consistent with this, the ion intensity of $\mathrm{Nb}_{3} \mathrm{O}_{7}{ }^{+}$shows minor increases when $\mathrm{Nb}_{3} \mathrm{O}_{8}{ }^{+}$is depleted, although most of the growth appears to come from fragmentation of larger clusters. The calculated dissociation energy of $2.56 \mathrm{eV}$ is the energy required for removing one $\mathrm{O}$ atom from the $\eta^{2}-\mathrm{O}_{2}{ }^{2-}$ unit of $\mathbf{V}$ and the formation of the $C_{3 v}$ symmetric isomer of $\mathrm{Nb}_{3} \mathrm{O}_{7}{ }^{+}(\boldsymbol{A})$. In comparison to the value of $0.9 \mathrm{eV}$ from CID experiments, ${ }^{8}$ the calculated fragmentation energy appears quite high. Nonetheless, IR-induced depletion of $\mathrm{Nb}_{3} \mathrm{O}_{8}{ }^{+}$can be achieved even at $5 \mathrm{~dB}$ attenuation of the IR laser $\left(0.32 I_{0}\right)$, whereas already at $3 \mathrm{~dB}$ attenuation $\left(0.50 I_{0}\right)$, depletion of $\mathrm{Nb}_{2} \mathrm{O}_{6}{ }^{+}$with a calculated dissociation energy of $1.30 \mathrm{eV}$ is no longer observable. Possibly, IVR is too slow for the smaller $\mathrm{Nb}_{2} \mathrm{O}_{6}{ }^{+}$cluster, which makes resonant multiple photon absorption less efficient.

5.3. $\mathrm{Nb}_{4} \mathrm{O}_{10}{ }^{+}$and $\mathrm{Nb}_{4} \mathrm{O}_{11}{ }^{+}$. For $\mathrm{Nb}_{4} \mathrm{O}_{10}{ }^{+}$it is reasonable to assume that its geometry is similar to that of neutral $\mathrm{V}_{4} \mathrm{O}_{10}$, which most likely has $T_{d}$ symmetry. ${ }^{22,31} \mathrm{We}$ find a minimum structure with $C_{1}$ symmetry; however the distortion relative to $T_{d}$ is small (see Figure 5d) and mainly caused by the presence 
of one terminal single-bonded $\mathrm{Nb}-\mathrm{O}$ unit, where the unpaired electron is located at the $\mathrm{O}$ atom. The calculated IR spectrum for this isomer of $\mathrm{Nb}_{4} \mathrm{O}_{10}{ }^{+}$is dominated by intense resonances at $800 \mathrm{~cm}^{-1}$ (doubly degenerate) and $819 \mathrm{~cm}^{-1}$, corresponding to stretch vibrations of $\mathrm{Nb}-\mathrm{O}-\mathrm{Nb}$ bridges. Combinations of terminal $\mathrm{Nb}=\mathrm{O}$ stretches lead to absorptions at 989, 990, and $1002 \mathrm{~cm}^{-1}$. The last one is the symmetric stretch vibration which would have no IR intensity in a $T_{d}$ structure and is calculated to be very weak here. All of these predictions are in good agreement with the experimental IR spectrum, which consists of a peak at $817 \mathrm{~cm}^{-1}$ with a width of $50 \mathrm{~cm}^{-1}$ (fwhm) and a narrower peak centered at $988 \mathrm{~cm}^{-1}$. In addition, the calculation predicts a comparatively weak signal at $670 \mathrm{~cm}^{-1}$ for the stretch of terminal $\mathrm{Nb}-\mathrm{O}$, but this is not observed experimentally.

In the case of $\mathrm{Nb}_{4} \mathrm{O}_{11}{ }^{+}$, the geometry optimizations of isomers derived from the $C_{1}$ symmetry $\mathrm{Nb}_{4} \mathrm{O}_{10}{ }^{+}$isomer by substituting one terminal $=\mathrm{O}$ unit by an end-on or side-on bonded dioxo group lead both to the same isomer XIIIa containing side-on bonded $\mathrm{O}_{2}$ with an $\mathrm{O}-\mathrm{O}$ bond length of $1.326 \AA$ (see Figure $5 \mathrm{e})$. Its symmetry is slightly distorted from $C_{s}$. In its doublet ground state, the spin density is equally distributed over the $\mathrm{O}_{2}$ group, characteristic for a superoxo $\eta^{2}-\mathrm{O}_{2}{ }^{-}$unit. An isomer XIIIb with an $-\mathrm{O}-\mathrm{O}-$ bridge is calculated to be $1.21 \mathrm{eV}$ higher in energy. The experimental $\mathrm{Nb}-\mathrm{O}-\mathrm{Nb}$ band of $\mathrm{Nb}_{4} \mathrm{O}_{11}{ }^{+}$ (see Figure 4) has a width of $90 \mathrm{~cm}^{-1}$ and consists of overlapping peaks. Reducing the IR intensity by $3 \mathrm{~dB}$ narrows this band to $50 \mathrm{~cm}^{-1}$, but does not result in resolved peaks. Still, the band shape is consistent with at least two peaks showing a maximum at $830 \mathrm{~cm}^{-1}$ and a shoulder at $850 \mathrm{~cm}^{-1}$. In the calculations, three absorptions in this region are found for XIIIa, at 796, 806, and $833 \mathrm{~cm}^{-1}$, all having comparable intensities. The behavior in the $\mathrm{Nb}=\mathrm{O}$ stretch region is similar to $\mathrm{Nb}_{4} \mathrm{O}_{10}{ }^{+}$, with three resonances at 989,991 , and $1003 \mathrm{~cm}^{-1}$. The $\mathrm{O}-\mathrm{O}$ stretch of XIIIa is calculated to be at $1152 \mathrm{~cm}^{-1}$ but has again low intensity and is not experimentally observed. Nevertheless, the calculated IR spectrum of XIIIa agrees well with the experimental findings. In comparison, the absorptions in the $\mathrm{Nb}-\mathrm{O}-\mathrm{Nb}$ stretch regions of isomer XIIIlb are more red-shifted, having resonance frequencies of 749, 807, and 823 $\mathrm{cm}^{-1}$. In the $\mathrm{Nb}=\mathrm{O}$ stretch region, four peaks are predicted covering the range $992-1008 \mathrm{~cm}^{-1}$.

The depletion of $\mathrm{Nb}_{4} \mathrm{O}_{10}{ }^{+}$coincides with intensity growth of several clusters, e.g., of $\mathrm{Nb}_{4} \mathrm{O}_{9}{ }^{+}$and $\mathrm{Nb}_{3} \mathrm{O}_{7}{ }^{+}$. The corresponding fragmentation channels might be $\mathrm{O}$ loss or fission under release of $\left\{\mathrm{NbO}_{2}, \mathrm{O}\right\}$. The latter reaction has been observed by CID at $5.3 \mathrm{eV}$ center-of-mass energy, accompanied by formation of $\mathrm{NbO}_{2}{ }^{+}$. At high collision energies and multicollision conditions $\mathrm{Nb}_{4} \mathrm{O}_{9}{ }^{+}$has been detected. ${ }^{8}$ Intensity growth of $\mathrm{Nb}_{4} \mathrm{O}_{8}{ }^{+}$has not been observed in our study excluding a fragmentation channel with $\mathrm{O}_{2}$ loss. In contrast, this reaction has been found as the major dissociation pathway for $\mathrm{V}_{4} \mathrm{O}_{10}{ }^{+}$ during IR-MPD. ${ }^{23}$ The fragmentation behavior of $\mathrm{Nb}_{4} \mathrm{O}_{11}{ }^{+}$will be discussed at the end of the following section.

5.4. Larger Clusters. The IR spectra of the larger niobium oxide cluster cations shown in Figure 4 exhibit sharp bands in the $\mathrm{Nb}=\mathrm{O}$ stretch region around $995 \mathrm{~cm}^{-1}$ and rather broad bands between 750 and $900 \mathrm{~cm}^{-1}$ in the $\mathrm{Nb}-\mathrm{O}-\mathrm{Nb}$ stretch region. Clusters with higher oxygen content have broader $\mathrm{Nb}-$ $\mathrm{O}-\mathrm{Nb}$ bands, indicating lower symmetry of the clusters. However, it is not always clear if the observed band shape is an intrinsic property, if it is an envelope of several peaks of one or more isomers, or if the depletion band is partially filled up by fragmentation.

For $\mathrm{Nb}_{5} \mathrm{O}_{13}{ }^{+}$the $\mathrm{Nb}-\mathrm{O}-\mathrm{Nb}$ band reaches from 700 to 880 $\mathrm{cm}^{-1}$. For this cluster, the depletion spectrum with $3 \mathrm{~dB}$ IR laser attenuation is measured to be weak and noisy but allows for identification of three peaks located at 753, 785, and 837 $\mathrm{cm}^{-1}$. For $\mathrm{Nb}_{6} \mathrm{O}_{16}{ }^{+}$one can recognize peaks at 820 and 860 $\mathrm{cm}^{-1}$, and for $\mathrm{Nb}_{7} \mathrm{O}_{18}{ }^{+}$three peaks might be located at 790, 833 , and $895 \mathrm{~cm}^{-1}$. However, depletion spectra with lower IR intensity in order to obtain better resolved spectra have not been measured for these clusters.

As already discussed, for the $\mathrm{Nb}=\mathrm{O}$ stretch absorption band a red-shift is found for the depletion signal relative to the "growth band". This shift of the depletion signal compared to the intensity increases due to fragment formation can only be explained if the absorption frequencies for larger clusters are blue-shifted compared to their fragments. Therefore, even if the exact positions of the band cannot be measured, the position of the $\mathrm{Nb}=\mathrm{O}$ band must shift with increasing cluster size and higher oxygen content to higher wavenumbers. It becomes clear already from the calculated IR spectra of the small cluster isomers that a shift to higher frequencies is indicative of an increasing $\mathrm{O}$-coordination of the corresponding $\mathrm{Nb}$ atoms. This is in agreement with the formation of compact cage structures, in which a higher coordination can be reached compared to open structures.

The ion intensity plots in Figures 3 and 4 show growth of cluster ion intensity especially for $\mathrm{Nb}_{4} \mathrm{O}_{9}{ }^{+}, \mathrm{Nb}_{5} \mathrm{O}_{12}{ }^{+}, \mathrm{Nb}_{7} \mathrm{O}_{17}{ }^{+}$, and $\mathrm{Nb}_{8} \mathrm{O}_{19}{ }^{+}$, indicating that these are preferential products of fragmentation. For the larger clusters it is more difficult to unambiguously identify the fragmentation pathways. Oxygenrich clusters with an odd number of niobium atoms $\left(\left(\mathrm{Nb}_{2} \mathrm{O}_{5}\right)_{n^{-}}\right.$ $\mathrm{NbO}_{3}{ }^{+}$) seem to fragment under release of atomic $\mathrm{O}$, while oxides with an even number of $\mathrm{Nb}$ atoms $\left(\left(\mathrm{Nb}_{2} \mathrm{O}_{5}\right)_{n} \mathrm{O}^{+}\right)$ dissociate to yield molecular $\mathrm{O}_{2}$. This behavior might indicate the actual bonding of a dioxo unit in the cluster. As found for the small clusters, the peroxo $\eta^{2}-\mathrm{O}_{2}{ }^{2-}$ group is split during fragmentation of $\mathrm{Nb}_{3} \mathrm{O}_{8}{ }^{+}$, whereas the superoxo $\eta^{1}-\mathrm{O}_{2}^{-}$in $\mathrm{Nb}_{2} \mathrm{O}_{6}{ }^{+}$remains "intact", yielding a $\mathrm{O}_{2}$ molecule. The calculated presence of the superoxo unit $\eta^{2}-\mathrm{O}_{2}{ }^{-}$in the isomer XIIIa of $\mathrm{Nb}_{4} \mathrm{O}_{11}{ }^{+}$agrees well with the loss of an $\mathrm{O}_{2}$ unit. In $\mathrm{O}_{2}{ }^{-}$the formal bond order is 1.5 , but it is only 1 in $\mathrm{O}_{2}{ }^{2-}$. Hence, much more energy is necessary to dissociate the $\mathrm{O}-\mathrm{O}$ bond in the superoxide compared to the peroxide, and the preferred fragmentation channel for $\mathrm{Nb}_{4} \mathrm{O}_{11}{ }^{+}$is loss of a complete $\mathrm{O}_{2}$ molecule, as found in earlier studies using $\mathrm{CID}^{8}$ and observed here in our study via IR-MPD.

\section{Summary and Conclusion}

Niobium oxide cluster cations undergo fragmentation when being resonantly excited with highly intense infrared radiation. The induced signal depletion allows for measurements of the corresponding IR spectra via IR-MPD spectroscopy. The experimental IR spectra are obtained for the (nearly) stoichiometric clusters $\left(\mathrm{Nb}_{2} \mathrm{O}_{5}\right)_{n}{ }^{+}$and $\left(\mathrm{Nb}_{2} \mathrm{O}_{5}\right)_{n} \mathrm{NbO}_{2}{ }^{+}(n=2,3)$ as well as for oxygen-rich clusters of typical compositions $\left(\mathrm{Nb}_{2} \mathrm{O}_{5}\right)_{n} \mathrm{O}^{+}$and $\left(\mathrm{Nb}_{2} \mathrm{O}_{5}\right)_{n} \mathrm{NbO}_{3}{ }^{+}(n=1-3)$. Narrow absorption bands at about $990-1000 \mathrm{~cm}^{-1}$ are assigned to stretches of isolated $\mathrm{Nb}=\mathrm{O}$ units, where the niobium atoms are 3- or 4-fold 
coordinated by $\mathrm{O}$ atoms. The stretch vibrations of $\mathrm{Nb}-\mathrm{O}-\mathrm{Nb}$ bridges are found in the $700-900 \mathrm{~cm}^{-1}$ range, varying with cluster size and stoichiometry.

For the smallest members of the oxygen-rich series, $\mathrm{Nb}_{2} \mathrm{O}_{6}{ }^{+}$ and $\mathrm{Nb}_{3} \mathrm{O}_{8}{ }^{+}$, the stabilities and harmonic frequencies of possible isomers are investigated theoretically and compared to the experimental results. For both oxide clusters, the most stable isomers contain dioxo units, superoxo $\eta^{1}-\mathrm{O}_{2}{ }^{-}$in $\mathrm{Nb}_{2} \mathrm{O}_{6}{ }^{+}$and peroxo $\eta^{2}-\mathrm{O}_{2}{ }^{2-}$ in $\mathrm{Nb}_{3} \mathrm{O}_{8}{ }^{+}$. Fragmentation channels indicate that in the larger clusters similar units are present, superoxo in $\left(\mathrm{Nb}_{2} \mathrm{O}_{5}\right)_{n} \mathrm{O}^{+}$and peroxo in $\left(\mathrm{Nb}_{2} \mathrm{O}_{5}\right)_{n} \mathrm{NbO}_{3}{ }^{+}$; however the IR absorption bands of the $\mathrm{O}-\mathrm{O}$ stretches are not detected for any cluster. Nevertheless, for $\mathrm{Nb}_{2} \mathrm{O}_{6}{ }^{+}$and $\mathrm{Nb}_{3} \mathrm{O}_{8}{ }^{+}$good agreement is obtained between the calculated IR spectrum of the energetically lowest isomers and the experimental spectrum, leading to structural identification of the oxide clusters present in the molecular beam.

The knowledge of the geometric structure of free oxide clusters provides an essential basis for understanding their gas phase reactions and is a general prerequisite for discussion of structure-reactivity relationships. In this study we focused mainly on oxygen-rich clusters containing dioxo species, which are probably not suited as active surface species to obtain selective catalytic hydrocarbon oxidation, but might be seen as intermediates of molecular oxygen activation. We are currently studying the reactions of niobium (and other transition metal) oxide clusters with hydrocarbons and will report the IR spectra of resulting oxide-cluster/hydrocarbons reaction products in a forthcoming paper.

Acknowledgment. This work is part of the research program of the "Stichting voor Fundamenteel Onderzoek der Materie" (FOM), which is financially supported by the "Nederlandse organisatie voor Wetenschappelijk Onderzoek" (NWO). Financial support from the EU IHP Research Training Network (Delayed Ionisation and Competing Cooling Mechanisms in Atomic Clusters) is gratefully acknowledged. A.F. thanks the Deutsche Forschungsgemeinschaft for a fellowship.

Supporting Information Available: Atom coordinates and vibrational frequencies. This material is available free of charge via the Internet at http://pubs.acs.org.

JA0288946 